\title{
Erratum: Anderson et al. (2019)
}

In the article Anderson, L., Close, G. L., Konopinski, M., Rydings, D., Milsom, J., Hambly, C., Speakman, J., Drust, B., \& Morton, J. P. (2019). Case Study: Muscle Atrophy, Hypertrophy, and Energy Expenditure of a Premier League Soccer Player During Rehabilitation From Anterior Cruciate Ligament Injury, International Journal of Sport Nutrition and Exercise Metabolism, 29(5),
559-566, https://doi.org/10.1123/ijsnem.2018-0391, on page 564, the variables under Energy (kcal/kg LBM) in Table 2 (Breakfast, Morning snack, Lunch, Afternoon snack, Dinner, and Evening snack) were listed with the incorrect unit of measurement. These variables were listed as measuring $\mathrm{CHO}(\mathrm{g})$ instead of $(\mathrm{kcal})$. The online version of this article has been corrected. 